\title{
Corneal Cross-Linking for Progressive Keratoconus in Children: Our Experience
}

\author{
Erez Bakshi, Yaniv Barkana, Yakov Goldich, Isaac Avni, David Zadok
}

\begin{abstract}
Purpose: To assess the effect of corneal cross-linking on progressive keratoconus in children.

Method: In this retrospective study we enrolled nine eyes of nine consecutive children aged 11 to 17 years old who underwent corneal riboflavin-UVA induced cross-linking for progressive keratoconus at the Department of Ophthalmology at Assaf Harofeh Medical Center. They were followed for 6 to 24 months (average $16 \pm 8.1$ months). Evaluated parameters were uncorrected visual acuity (UCVA), best spectacle-corrected visual acuity (BSCVA), manifest refraction, pachymetry, slit lamp examination and corneal topography.
\end{abstract}

Results: Cross-linking resulted in stability of visual acuity in seven of the nine $(77.8 \%)$ treated eyes. We found a nonsignificant improvement in UCVA and BSCVA with a small reduction of manifest cylinder. Furthermore, there was an improvement in spherical equivalent that was close to statistical significance $(p=0.07)$. There was $0.86 \mathrm{D}$ reduction of average Kmax value postoperatively $(p=0.36)$. Most patients (7 of 9 , $77.8 \%$ ) showed a long-term stability or reduction in Kmax.

Conclusion: In this study, we demonstrated the efficacy of corneal cross-linking in arresting the progression of keratoconus in children. We believe that larger scale studies in this age group should be performed to further establish the relevance of this technique in children.

Keywords: Keratoconus, UVA, Collagen corneal cross-linking.

How to cite this article: Bakshi E, Barkana Y, Goldich Y, Avni I, Zadok D. Corneal Cross-Linking for Progressive Keratoconus in Children: Our Experience. Int J Keratoco Ectatic Corneal Dis 2012;1(1):53-56.

\section{Source of support: Nil}

Conflict of interest: None declared

\section{INTRODUCTION}

Keratoconus is a noninflammatory process leading to corneal ectasia which also involves corneal thinning and biomechanical weakening. These changes may result in visual impairment due to irregular astigmatism, progressive myopia or corneal stromal scarring. ${ }^{1,2}$ Keratoconus in its early stages is usually managed by optical correction, using either glasses or more commonly gas-permeable contact lenses. In cases of unsatisfactory best-corrected visual acuity (BCVA) or contact lens intolerance, surgical intervention may be required and the estimated risk of needing corneal transplantation is 10 to $20 \%{ }^{3,4}$

In recent years, an emerging and seemingly promising technique, corneal cross-linking (CXL), has been introduced, indicated for halting the progression of keratoconus. In this minimally invasive procedure, the administration of riboflavin on deepithelialized cornea is followed by ultraviolet A (UVA) light, an interaction leading to enhancement of corneal stiffening., ${ }^{5,6}$

Currently, the acceptable criteria for CXL include a significant increase in maximal keratometry (Kmax) and a minimum corneal thickness of $400 \mu \mathrm{m}$ in patients older than 12-year-old. ${ }^{7}$ Even though there are no specific criteria for the pediatric population, taking into consideration the inverse correlation between severity and age ${ }^{8}$ it appears that early intervention may be necessary for some children, and CXL should thus be considered.

In this study, we retrospectively analyzed visual acuity, refractive and topographic outcomes in pediatric patients with progressive keratoconus during up to 2-year postoperative period.

\section{PATIENTS AND METHODS}

In this retrospective study, we enrolled consecutive patients using the following inclusion criteria: Age younger than 18 years at the time of the procedure, progressive keratoconus and corneal thickness of at least $400 \mu \mathrm{m}$. Progression was defined as an increase of at least 1.5D in astigmatic refraction and/or maximum curvature documented by corneal topography at 3 time points within the past 12 months.

Patients were assessed preoperatively and at week 1 , months 1, 3, 6, 12 and 24 after treatment. Each examination included measurement of UCVA, BSCVA, manifest refraction, slit lamp and dilated fundus examination and corneal topography. Topography measurements were obtained using a rotating Scheimpflug camera (Pentacam, Oculus, Inc). Recorded parameters were maximum, minimum and average $\mathrm{K}$ values (Kmax, Kmin and Kave respectively), corneal astigmatism (simulated K) and corneal thickness.

\section{Surgical Technique}

All procedures were performed by the same surgeon (DZ) using the surgical technique recommended by Theo Seiler and his group. ${ }^{5}$

Patients were treated with UVA-riboflavin CXL under aseptic conditions using topical preoperative anesthesia with 
oxybuprocaine hydrochloride 0.4\% drops (Localin, Fisher Pharmaceutical Labs). Treatment included $7 \mathrm{~mm}$ diameter corneal deepithelization, instillation of riboflavin $0.1 \%$ in dextran 20\% solution (Peschke Meditrade GmbH, Switzerland) every 5 minutes for 30 minutes and corneal irradiation with UVA $3 \mathrm{~mW} / \mathrm{cm}^{2}$ (UV-X ${ }^{\mathrm{TM}}$ Peschke Meditrade GmbH, Switzerland) for 30 minutes, $5 \mathrm{~cm}$ from the cornea with persistent application of $0.1 \%$ riboflavin in $20 \%$ dextran solution drops. After the procedure, patients were treated with a topical antibiotic (oflox, ofloxacin $0.3 \%$, allergan) 4 times a day for 7 days and a topical corticosteroid (sterodex, dexamethasone 0.1\%, Fisher Pharmaceutical Labs) 4 times a day for 1 month, and the eye was dressed with a soft therapeutic contact lens (Ocular Sciences Ltd, Southampton, UK) for 3 days. UV-irradiance was checked preoperatively in each case using a UV-meter.

\section{STATISTICAL ANALYSIS}

Statistical analysis was performed with SPSS software (version 16, SPSS Inc) and the data was analyzed using the 2-tailed t-test for each parameter. Data is expressed as mean differences between pre and post for each parameter.

\section{RESULTS}

Nine eyes of nine patients had CXL and were followed for a period of 6 to 24 months (average $16 \pm 8.1$ months). Six eyes (66.7\%) completed more than 12 months of follow-up. All patients were male with a mean age of $14 \pm 1.87$ years (range 11-17). Table 1 details patients' more information. Neither intraoperative nor postoperative complications were encountered, with the exception of corneal haze in one case that resolved completely with topical steroidal treatment after 8 weeks.

Figures 1 to 4 present data concerning visual acuity and manifest refraction before and after treatment. There was a nonsignificant improvement in UCVA $(0.92 \pm 0.39$ preoperatively and $0.86 \pm 0.36$ postoperatively, $\mathrm{p}=0.4$ ) and BSCVA $(0.34 \pm 0.27$ preoperatively and $0.27 \pm 0.14$

Table 1: Demographic and general information

\begin{tabular}{cccc}
\hline $\begin{array}{c}\text { Patient } \\
\text { number }\end{array}$ & $\begin{array}{c}\text { Age at time of } \\
\text { CXL (years) }\end{array}$ & $\begin{array}{c}\text { Treated } \\
\text { eye }\end{array}$ & $\begin{array}{c}\text { Time of } \\
\text { follow-up } \\
\text { (months) }\end{array}$ \\
\hline 1 & 15 & $\mathrm{Lt}$ & 24 \\
2 & 15 & $\mathrm{Lt}$ & 24 \\
3 & 13 & $\mathrm{Rt}$ & 6 \\
4 & 13 & $\mathrm{Rt}$ & 24 \\
5 & 15 & $\mathrm{Rt}$ & 24 \\
6 & 12 & $\mathrm{Rt}$ & 15 \\
7 & 11 & $\mathrm{Lt}$ & 9 \\
8 & 17 & $\mathrm{Rt}$ & 6 \\
9 & 15 & $\mathrm{Lt}$ & 12 \\
\hline
\end{tabular}

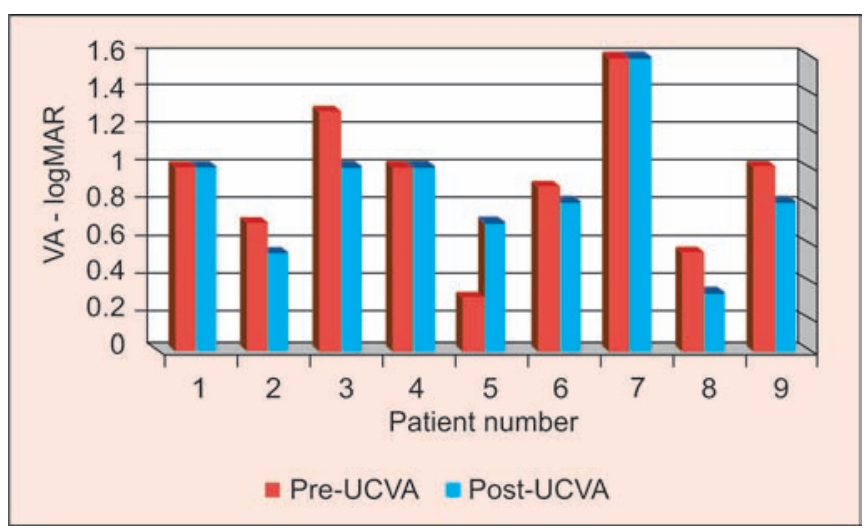

Fig. 1: Uncorrected visual acuity pre- and postoperatively

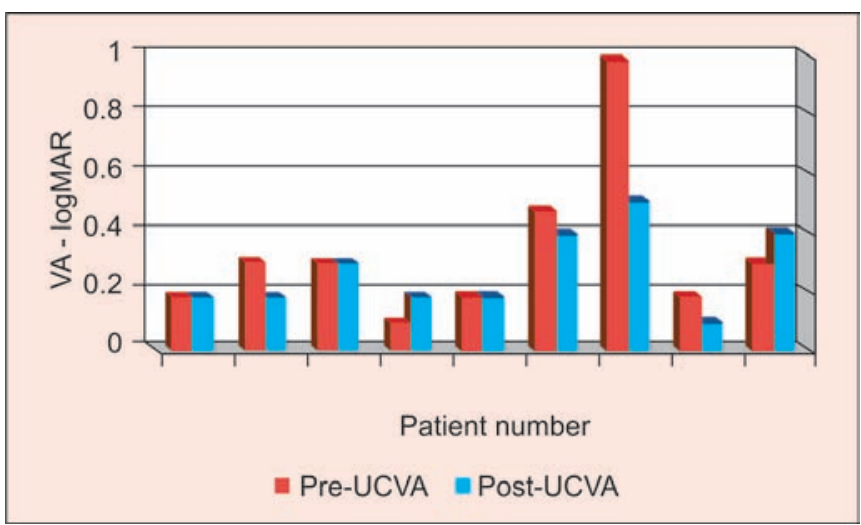

Fig. 2: Best spectacle-corrected visual acuity pre- and postoperatively

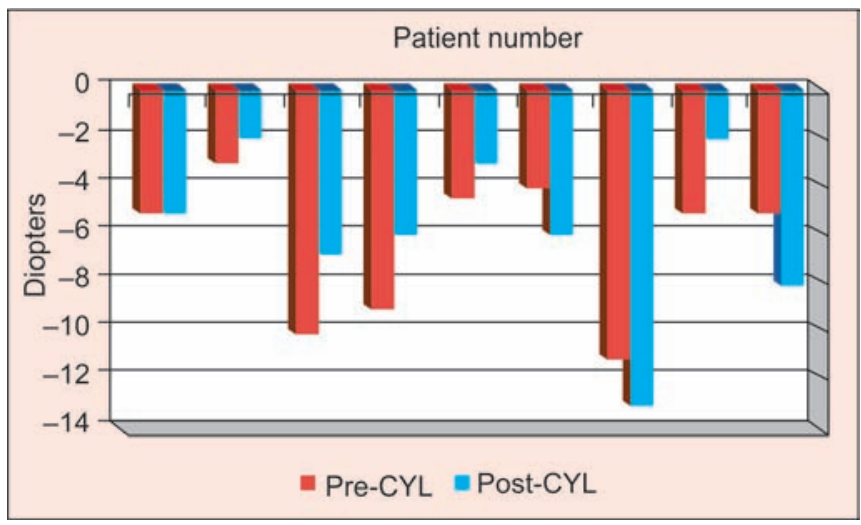

Fig. 3: Cylinder power pre- and postoperatively

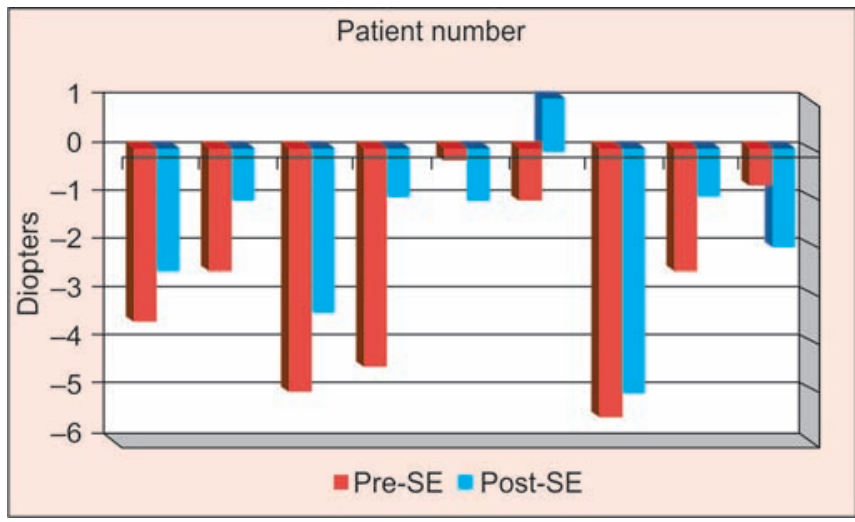

Fig. 4: Spherical equivalent pre- and postoperatively 
Corneal Cross-Linking for Progressive Keratoconus in Children: Our Experience

Table 2: Kmax, Kmin and Kave pre- and postoperatively

\begin{tabular}{lcccccc}
\hline $\begin{array}{l}\text { Patient } \\
\text { number }\end{array}$ & $\begin{array}{c}\text { Kmax } \\
\text { preoperative }\end{array}$ & $\begin{array}{c}\text { Kmax } \\
\text { postoperative }\end{array}$ & $\begin{array}{c}\text { Kmin } \\
\text { preoperative }\end{array}$ & $\begin{array}{c}\text { Kmin } \\
\text { postoperative }\end{array}$ & $\begin{array}{c}\text { Kave } \\
\text { preoperative }\end{array}$ & $\begin{array}{c}\text { Kave } \\
\text { postoperative }\end{array}$ \\
\hline 1 & 62.68 & 62.3 & 47.93 & 51.5 & 55.31 & 56.9 \\
2 & 54.93 & 56 & 39.7 & 40.5 & 47.32 & 48.25 \\
3 & 56.71 & 57.3 & 47.32 & 48.9 & 52.02 & 53.1 \\
4 & 57.24 & 59 & 43.63 & 44.1 & 50.44 & 51.55 \\
5 & 56.66 & 55.1 & 46.37 & 45.5 & 51.52 & 50.3 \\
6 & 62.7 & 62.9 & 45.91 & 46.3 & 54.20 & 54.6 \\
7 & 63.13 & 56.6 & 51.42 & 50.3 & 57.28 & 53.45 \\
8 & 62.15 & 59 & 45.28 & 48.05 & 53.72 & 53.525 \\
9 & 52.48 & 52.77 & 43.69 & 43.05 & 48.09 & 47.91 \\
\hline Average & 58.74 & 57.89 & 45.69 & 46.47 & 52.21 & 52.18 \\
\hline
\end{tabular}

postoperatively, $\mathrm{p}=0.29$ ). Most patients (7 of 9, 77.8\%) showed a long-term stability or improvement in BCVA. There was a nonsignificant hyperopic shift in sphere (0.44D preoperatively and 1.17D postoperatively, $\mathrm{p}=0.16)$ and a decrease in cylinder (6.28D preoperatively and 5.75D postoperatively, $\mathrm{p}=0.52$ ). However, there was a decrease in postoperative spherical equivalent that was close to statistical significance (-2.69D preoperatively and $-1.71 \mathrm{D}$ postoperatively, $\mathrm{p}=0.07$ ).

There was $0.86 \mathrm{D}$ reduction of average Kmax value postoperatively but with no statistical significance $(\mathrm{p}=0.36)$. Most patients (7 of 9, 77.8\%) showed a long-term stability or reduction in Kmax. No significant change in the Kmin $(p=0.19)$ or Kave $(p=0.95)$ was observed (Table 2$)$.

\section{DISCUSSION}

Corneal cross-linking with riboflavin and UVA has recently become a part of our arsenal in the management of keratoconus, and several studies have demonstrated its role in halting the progression and even in reducing the need for keratoplasty. ${ }^{5,9,10}$ It has been shown that CXL is capable of improving both corneal topographic indices and visual acuity, beginning 2 to 3 months postoperatively and gaining stability after 24 months, ${ }^{11-13}$ with encouraging safety. ${ }^{14,15}$

To the best of our knowledge, there is only one publication in the literature regarding CXL in pediatric keratoconus, in which five eyes of four children with rapidly progressive keratoconus were reported. The general impression of the authors was that CXL has successfully achieved regression or at least stabilization of the Kmax and BCVA. ${ }^{16}$

In the present retrospective study, we did not observe a significant improvement in corneal topographic indices, but we observed stability in BSCVA during the relatively long follow-up period. The weakness of this study is ofcourse the small number of cases included, a fact that may be responsible for the statistical insignificance of our results.
Alternatively, it may be explained by a possible difference in corneal biomechanical properties and thus, response to treatment in the pediatric population. We cannot ignore the fact that a borderline- significant decrease in post-operative SE was demonstrated, and it seems that further studies with a larger number of pediatric participants may aid in elucidating this fascinating issue.

\section{CONCLUSION}

The results of this study are in general support of previously published data regarding the safety index and the stabilizing effect of CXL on visual acuity, refraction and corneal indices. We therefore believe that CXL may have an important role in the pediatric keratoconic population, in which the rate and speed of progression are a significant issue.

\section{REFERENCES}

1. Krachmer JH, Feder RS, Belin MW. Keratoconus and related noninflammatory corneal thinning disorders. Surv Ophthalmol 1984;28:293-322.

2. Rabinowitz YS. Keratoconus. Surv Ophthalmol 1998;42: 297-319.

3. Troutman RC, Lawless MA. Penetrating keratoplasty for keratoconus. Cornea 1987;6:298-305.

4. Lim L, Pesudovs K, Coster DJ. Penetrating keratoplasty for keratoconus: Visual outcome and success. Ophthalmology 2000;107:1125-31.

5. Wollensak G, Spoerl E, Seiler T. Riboflavin/ultraviolet-A induced collagen cross-linking for the treatment of keratoconus. Am J Ophthalmol 2003;135:620-27.

6. Wollensak G, Spoerl E, Seiler T. Stress-strain measurements of human and porcine corneas after riboflavin/ultraviolet-A induced collagen crosslinking. J Cataract Refract Surg 2003;29: 1780-85.

7. FDA clinical trials. 1st September 2010. Cross-linking of corneal collagen (CXL) with ultraviolet-A in asymmetric corneas. http:// clinicaltrials.gov/ct2/show/NCT01189864? term=FDA+ crosslinking\&rank $=1$.

8. Ertan A, Muftuoglu O. Keratoconus clinical findings according to different age and gender group. Cornea 2008;27:1109-13. 
9. Caporossi A, Baiocchi S, Mazzotta C, et al. Parasurgical therapy for keratoconus by riboflavin-ultraviolet type A induced crosslinking of corneal collagen: Preliminary refractive results in an Italian study. J Cataract Refract Surg 2006;32:837-45.

10. Mazzotta C, Traversi C, Baiocchi S, et al. Corneal healing after riboflavin-ultraviolet-A cross-linking determined by confocal laser scanning microscopy in vivo: Early and late modifications. Am J Ophthalmol 2008;146:527-33.

11. Greenstein SA, Fry KL, Hersh PS. Corneal topography indices after corneal collagen cross-linking for keratoconus and corneal ectasia: One-year results. J Cataract Refract Surg 2011;37: 1282-90.

12. Caporossi A, Mazzotta C, Baiocchi S, et al. Long-term results of riboflavin ultraviolet-A corneal collagen cross-linking for keratoconus in Italy: The Siena eye cross study. Am J Ophthalmol 2010;149:585-93.

13. Raiskup-Wolf F, Hoyer A, Spoerl E, et al. Collagen cross-linking with riboflavin and ultraviolet-A light in keratoconus: Longterm results. J Cataract Refract Surg 2008;34:796-801.

14. Spoerl E, Mrochen M, Sliney D, et al. Safety of UVA-riboflavin cross-linking of the corneal. Cornea 2007;26:385-89.

15. Goldich Y, Marcovich AL, Barkana Y, Avni I, Zadok D. Safety of corneal collagen cross-linking with UVA and riboflavin in progressive keratoconus. Cornea Apr 2010;29(4):409-11.
16. Soeters N, Van der Lelij A, Van der Valk R, et al. Corneal crosslinking for progressive keratoconus in four children. J Pediatr Ophthalmol Strabismus 2011;48:e26-29.

\section{ABOUT THE AUTHORS}

\section{Erez Bakshi}

Department of Ophthalmology, Assaf Harofeh Medical Center, Israel

\section{Yaniv Barkana}

Department of Ophthalmology, Assaf Harofeh Medical Center, Israel

\section{Yakov Goldich}

Department of Ophthalmology, Assaf Harofeh Medical Center, Israel

\section{Isaac Avni}

Department of Ophthalmology, Assaf Harofeh Medical Center, Israel

\section{David Zadok (Corresponding Author)}

Department of Ophthalmology, Assaf Harofeh Medical Center, Israel e-mail:dzadok@yahoo.com 